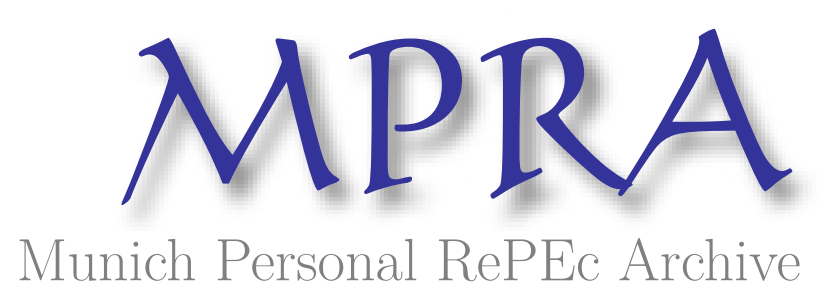

\title{
Slope versus elasticity and the burden of taxation
}

Graves, Philip E. and Sexton, Robert L. and Lee, Dwight R.

University of Colorado, Pepperdine University, University of Georgia

1996

Online at https://mpra.ub.uni-muenchen.de/19908/

MPRA Paper No. 19908, posted 11 Jan 2010 07:43 UTC 


\title{
Slope Versus Elasticity and the Burden of Taxation
}

\author{
Philip E. Graves, Robert L. Sexton, \\ and Dwight R. Lee
}

That the incidence of a tax does not depend on who "nominally" pays it, the buyer or the seller, is something that is always of interest to beginning students of economics. In typical textbook explanations of the incidence of an excise tax, who actually pays the tax on a good is seen to depend on the elasticities of the demand and supply curves. Indeed, the treatment of tax incidence is invariably used as one of the important applications of the elasticity construct.

Although no approach is free of potential for confusion, we feel that a clearer explanation of tax incidence for most purposes lies in the slope of the supply and demand curves, rather than with (or at least in addition to) their elasticities. The most important reason for this view is that some instructors, particularly those teaching short courses or combined micro-macro courses, may wish to cover tax incidence-without taking up elasticities. Another reason is that, having carefully made the (always confusing) point that "elasticity is not the same thing as slope," presenting tax incidence solely as an elasticity concept may lead the student to (wrongly) assume it cannot be understood merely with slopes. Finally, we think the approach to tax incidence employing slope is simpler and less confusing in its own right, especially because the fact that "relative" elasticities are what matter is seldom clearly spelled out.

A sampling of textbooks in both the principles and intermediate markets confirms the impression that elasticities (implicitly not slopes) determine the burden of a tax. The following is a sampling of chapter subheadings in popular textbooks: "Tax Division and Elasticity of Demand" (Parkin 1993, 138), "Using the Concept of Elasticity - the Burden of a Tax" (Gwartney and Stroup 1992, 149), "Elasticity and Tax Incidence" ((McConnell and Brue 1993, 333), "Elasticity and Tax Incidence: An Application" (McEachern 1994, 454), and "Who Pays the Tax: Elasticity Matters" (Arnold 1992, 459). Other authors have written: "[T]he effect of a tax on a good depends on the elasticity of supply and demand" (Stiglitz $1993,621)$; "The greater is the elasticity of demand, the less of the tax burden is borne by the buyers, ceteris paribus" (Katz and Rosen 1991, 375); and the "impact of a tax depends on the elasticities of supply and demand" (Pindyck and Rubinfeld 1992, 316). In addition to principles and intermediate microeconom-

Philip E. Graves is a professor of economics at the University of Colorado, Robert L. Sexton is a professor of economics at Pepperdine University, and Dwight R. Lee is the Ramsey Professor of Economics at the University of Georgia. The authors would like to thank two anonymous referees for their helpful comments. 
ics textbooks, similar citations could be made to public finance textbooks. The common theme is that of focusing exclusively on elasticity, rather than slope, as the determinant of tax incidence.

\section{TAX BURDEN AND THE SLOPE}

The potential for confusion raised in this article is perhaps best illustrated by the simple case depicted in Figure 1. Note that the incidence of a producer-paid tax, readily seen from the slopes, is identical regardless of whether one considers demand curve $D_{1}, D_{2}$, or $D_{3}$. However, as will be clear to any student who has been drilled on how elasticity varies along a straight-line demand curve, the demand elasticity at the initial price is progressively smaller as we move outward among the curves. Hence, there is considerable potential for confusion by relying exclusively on elasticity in the discussions of tax incidence.

It is not, of course, that the various authors are "wrong" in their presentations of elasticity. ${ }^{1}$ At any point the result will be equivalent-but the subtlety of this fact will be unclear to all but the best readers. Most students will have a vague (and accurate) sense that tax incidence can be most readily seen directly from the slopes of the curves - they will also know that elasticity varies along a straight line demand curve. This latter insight may lead them to be confused, for if the demand

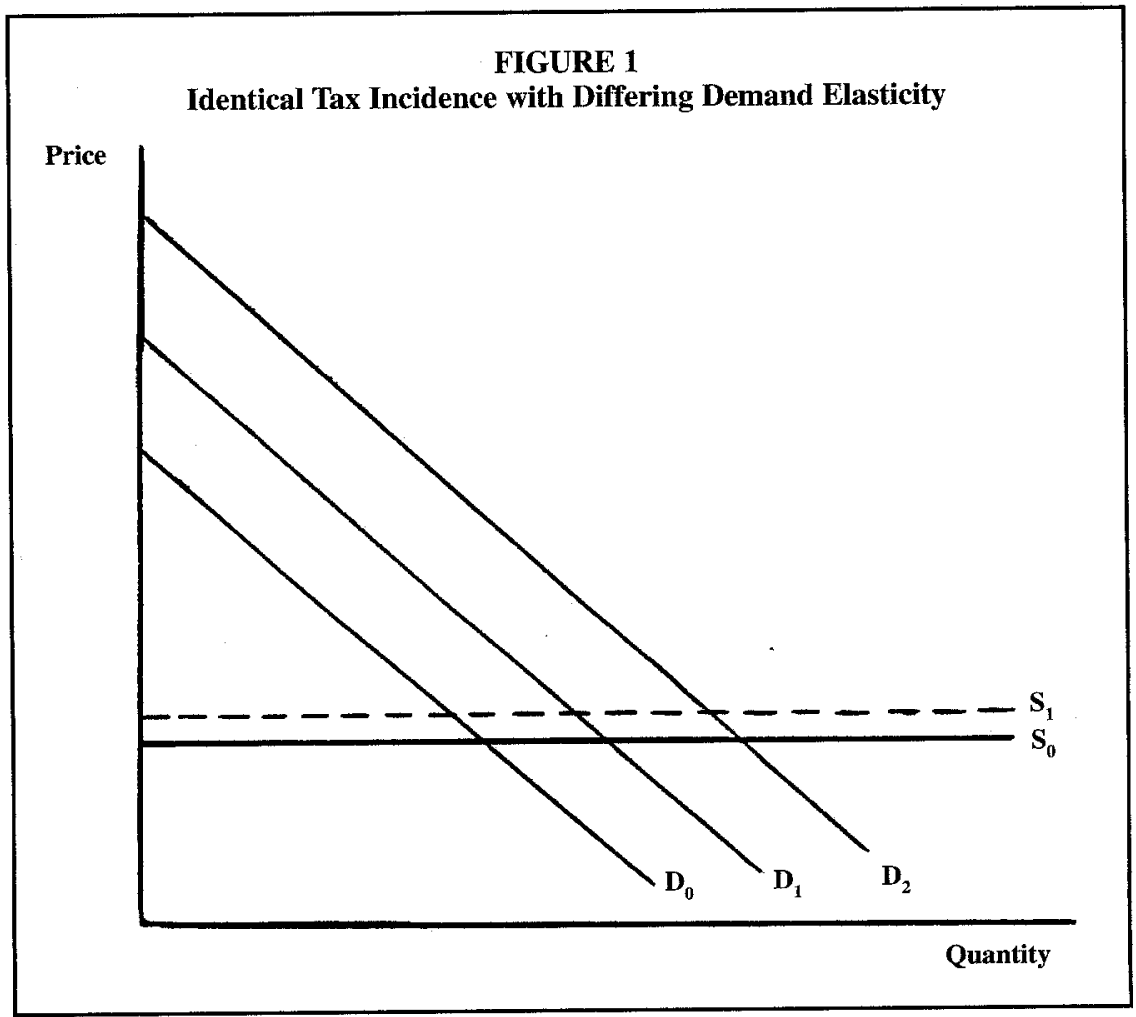


elasticity is varying as in Figure 1, how can tax incidence be unaffected?

The nature of the confusion may be further clarified by examination of Figures $2 \mathrm{a}$ and $2 \mathrm{~b}$. In $2 \mathrm{a}$, a unit-elastic demand curve is drawn with three alternative supply curves, $S_{0}$ (also unitary elastic), $S_{1}$ (elasticity greater than 1 ), and $S_{2}$ (elasticity less than 1). It would be quite easy to see for small upward shifts in supplyusing only slope - that the tax burden is split equally when considering $D$ and $S_{0}$. Relatively more of the tax is passed on to demanders if the supply curve is like

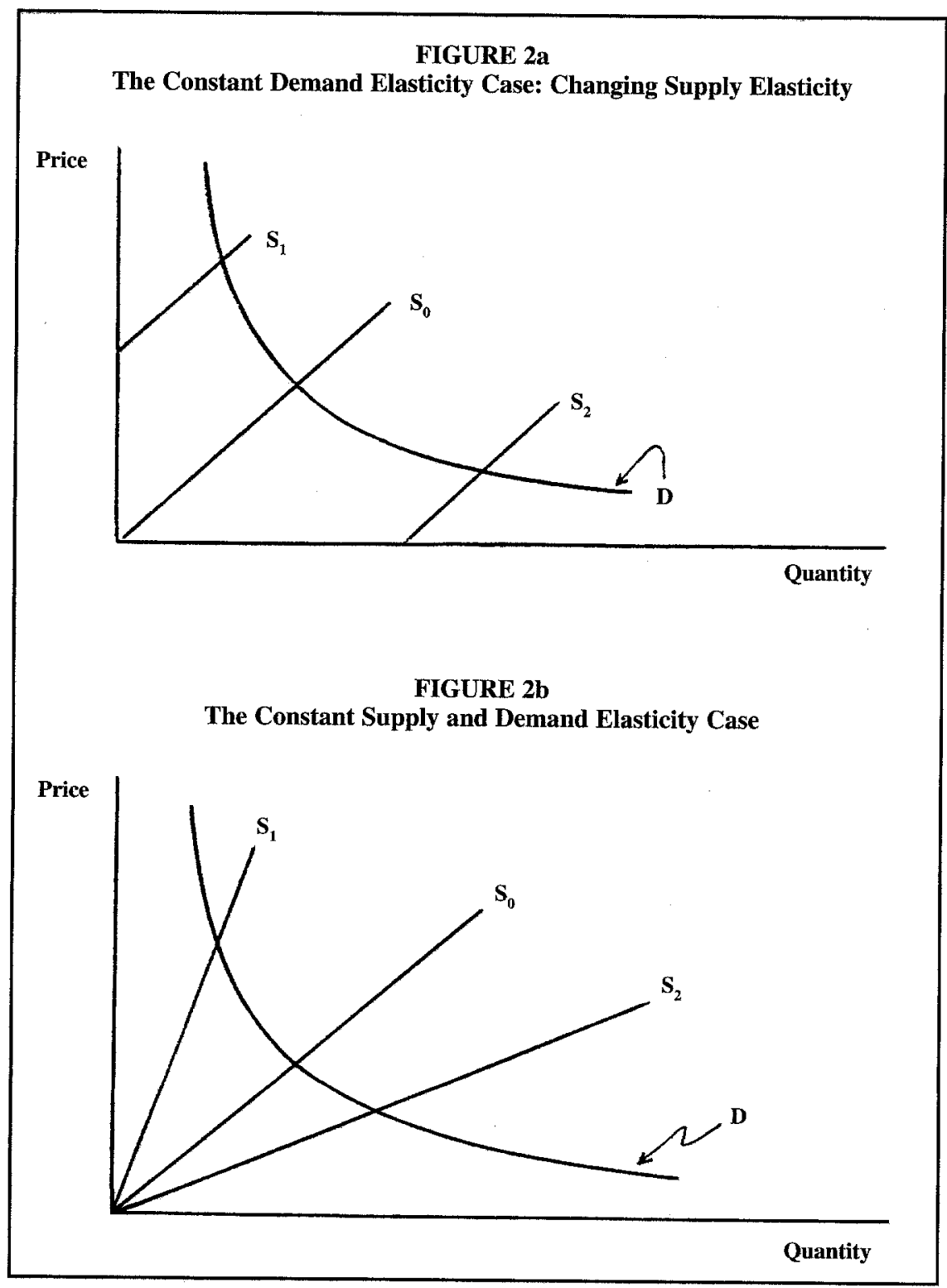


$S_{1}$, whereas the converse is true for $S_{2}$. To make the same evaluations with the elasticity approach requires that the student first determine the relative elasticities of the supply curves, all of which might "look pretty much the same."

The same point can be made another way in Figure 2b. Here, a small shift in any of the supply curves because of a tax can be readily seen, using only slope, to lead to an even split of the burden between demanders and suppliers. To use the elasticity approach, one must first recognize that the elasticities of all three supply curves are the same (they are linear and go through the origin), in spite of the fact that, to the student, they will "look very different."

\section{SUMMARY}

We know of no textbook that discusses tax incidence using the slopes of the demand and supply curves, in spite of the fact that this is the simplest and easiest way to clarify tax incidence. Elasticity can be used to discuss tax incidencealthough it is relative elasticity that matters as Figure 1 demonstrates-but this approach is more complicated. ${ }^{2}$ We would recommend in future revisions of principles textbooks that, at a minimum, slopes be presented as a way of determining tax incidence; this is of particular importance to those wishing to deal with tax incidence without considering elasticity. In more advanced treatments, a presentation analogous to that here might prove useful in giving the student a full understanding of tax incidence.

\section{NOTES}

1. The reason Figure 1 is confusing is that the "relative" elasticities are the same at the three intersections, because the supply elasticity is infinite in the diagram. This is, however, not a trivial case in light of its importance for long-run concerns.

2. Much like the desire for peaceful uses of atomic reactions, having introduced the elasticity concept to students, perhaps we strive too hard to find applications!

\section{REFERENCES}

Arnold, R. 1992. Economics, 2d ed. St. Paul, Minn.: West.

Gwartney, J., and R. Stroup. 1992. Microeconomics: Private and public choice, 6th ed. Fort Worth, Tex.: Dryden Press.

Katz, M., and H. Rosen. 1991. Microeconomics. Homewood, Ill.: Irwin.

McConnell, C., and S. Brue. 1993. Microeconomics, 12th ed. New York: McGraw-Hill.

McEachern, W. 1994. Economics: A contemporary introduction. Cincinnati, Ohio: South-Western.

Parkin, M. 1993. Microeconomics, $2 d$ ed. Reading, Mass.: Addison Wesley.

Pindyck, R., and D. Rubinfeld. 1992. Microeconomics, 2d ed. New York: Macmillan.

Stiglitz, J. 1993. Principles of microeconomics. New York: W. W. Norton. 